\title{
Идентификация волновых закономерностей поведения
}

Mazurkin P.M., Doctor of Technical Sciences, Professor, Academician of the Russian Academy of Natural Sciences, Member of the European Academy of Natural Sciences, Volga State Technological University, Yoshkar-Ola, Russia, E-mail: kaf_po@mail.ru

Сгруппированные данные. В статье ${ }^{1}$ применен широко известный метод линейной регрессии. Он предполагает группировку первичных исходных данных. Такая процедура сглаживает ряд данных и исключает из анализа колебательные возмущения значений изучаемого параметра системы. В итоге возможны ошибки в интерпретации результатов экспериментов.

Мы провели по сгруппированным (nmeth.2724-f3.xls ${ }^{1}$ ) данным идентификацию устойчивыми законами (Add. material 1.doc) и показали разницу в адекватности по коэффициенту корреляции (Primer.xls). По адекватности нелинейные тренды и линейная модель на сгруппированных выборках почти одинаковы. Дополнение нелинейного тренда волновыми составляющими (в виде асимметричных вейвлетов) повышает тесноту факторной связи в 5-13 раз.

Графики по моделям даны на рисунке 1. Параметры общего вейвлет-сигнала приведены в матричной форме (Table 1.doc) с пятью значащими цифрами мантиссы числа. Обобщенный «кирпичик» Гильберта (Fig. 1a) применяется и при моделировании любых колебательных возмущений (Fig. 1b) как функция амплитуды (половина) и полупериода. С увеличением количества составляющих модель получает большее значение коэффициента корреляции (Fig. 1c, d). Из-за малого числа сгруппированных значений показателя коэффициент корреляции может быть равным 1,0000 (Fig. 1e). Поэтому желательны первичные данные. Все модели имеют адекватность не менее 0,8 (Fig. 1f-i) по коэффициенту корреляции.

Первичные данные. Здесь нет усреднений (Fig. 2, Table 1, Add. material 2), поэтому мощность выборки (максимум до 3500) достаточна для получения более достоверных по тесноте связи биотехнических закономерностей. Изменения thyA KO (Fig. 2a) и WT (Fig. 2b) при Seed1 описываются трендом, содержащим разность между двумя законами экспоненциальной гибели (закон Лапласа в математике, Мандельброта в физике, Ципфа в биологии и Паре- 
то в экономике). Пространственные графики (Fig. 2c, d) показывают, что thyA Bound после некоторого значения дает предельно максимальные значения thyA KO $\vee$ WT. Тогда обособленно можно рассмотреть однофакторные зависимости thyA KO $\vee$ WT $=f($ Seed1-7).

Неизвестная закономерность. Авторы статьи ${ }^{1}$ дали простое перечисление Seed от 1 до 7. но оказалось (Fig. 2e, f), что здесь присутствует новый влияющий фактор (семь концентраций субстрата, а также время проведения опытов, которое нужно было фиксировать). Тренд и один вейвлет-сигнал (Online Metod.doc) дают коэффициент корреляции по обоим показателям 0,9999. При этом видно, что гены адаптируются во времени к субстрату: вначале они в поведении увеличивают амплитуду асимметричного колебания, а после гасят возмущение.

На границе thyA Bound max (Fig. 2g, h) появляется четкая зависимость типа thyA KO $\vee$ WT = $\mathrm{f}($ Seed1-7; thyA Bound max). Причем при переходе от thyA KO $\vee$ к WT происходит проявление некой энергетической ямы в виде дна условного сосуда. При этом боковая поверхность этого условного сосуда может быть продолжена при условии Seed $>7$.

Wavelet-analyze. Вейлет-анализ начинается с идентификации тренда (Fig. 3a), а затем выявляется асимметричный вейлвет (Fig. 3b). После этого две части объединятся в одну формулу (Fig. 3c). Закономерность $10^{-3}$ Mod SD $=f\left(10^{-3}\right.$ Expt SD) (Table 1) включает большее количество волн возмущения. По остаткам от двухчленной формулы (Fig. 3d-f) снова идентифицируется второй вейвлет (Fig. 3g). Затем три члена объединяются для получения эффекта «встряски» (Fig. 3h). Дальше возможности CurveExpert ограничены (всего 19 параметров модели). Поэтому каждый последующий вейвлет выявляется заново (Fig. 3i-n).

Затем появляются аномально расположенные относительно оси абсцисс точки: при одном $x$ появляются числа $y$ с разными знаками. Для $10^{-3}$ Mod SD $=\mathrm{f}\left(10^{-3} \operatorname{Expt} \mathrm{SD}\right)$ получились 6 то-

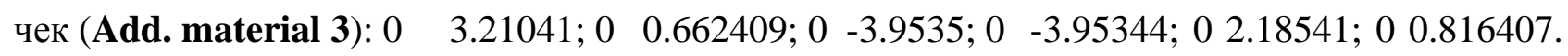
Дополнительные вейвлеты (Fig. 3o) можно продолжить дальше, если разрешить противоречие при нуле $x$. Нужно будет только уточнить методику измерений при условии $x=0$. 
Вейвлет-анализ также был выполнен по всем 526 генам (Fig. 4, Add. material 4). Прямая функция $10^{3}$ Mod SD = f(10 $\operatorname{Mod}$ Mean) с четырьмя членами имеет коэффициент корреляции 0.9029, а обратная зависимость $10^{3}$ Mod Mean $=\mathrm{f}\left(10^{3}\right.$ Mod SD $)$ меру тесноты связи 0.9448. На графиках прямой функции (Fig. 4a-d) видно пять кластеров, а обратной (Fig. 4e-h) - четыре.

Обсуждение. Многие биотехнические закономерности имеют до 100 составляющих, и их количество зависит от точности опытов и отсутствия всякой группировки исходных данных. На основе априорной инофрмации ${ }^{1}$ нами была получена принципиально новая апостериорная информация, полученная в ходе идентификации устойчивых биотехнических закономерностей (Table 1), об адаптационных способностях генов. Для дальнейшего изучения популяционной динамики генов необходима табличная модель (числовое поле) по всем изученным в статье ${ }^{1} 525$ генам. При этом в одном из столбцов таблицы должен быть фактор времени эксперимента. Тогда появится возможность полного факторного анализа, что позволило бы узнать еще больше о поведении всей популяции генов.

\section{METODS}

Метод идентификации (Online Metod) предполагает малую погрешность измерений и высокую полноту функционального каркаса эксперимента. Таким высоким качеством обладают массивы исходных первичных данных ${ }^{1}$. Коэффициент корреляции 0.9999 (Table 1, Fig. 2e, f) даже выше адекватности статистического моделирования рядов целых простых чисел ${ }^{10}$.

1. Jayodita C Sanghvi1 et al. Accelerated discovery via a whole-cell model. Nat. Methods. Published online 3 November 2013 | doi:10.1038/nmeth.2724. 